\title{
Caminhos da memória e do conhecimento histórico escolar: reinventando a aula de História com a criação de um roteiro histórico local e o uso do QR code
} Paths of Memory and Historical School Knowledge:
Reinventing History Classes by making a
Local Historical Itinerary using QR code

Alessandra Soares Santos*

Renato Sena Ramos ${ }^{\star *}$

\section{RESUMO}

O artigo discute a produção do conhecimento histórico escolar por meio de uma prática que permitiu às/aos estudantes exercitar a pesquisa, a análise crítica, a interpretação e a construção de representações qualificadas do passado no presente. Desenvolvido nos anos finais do ensino fundamental de uma escola da rede pública municipal de Belo Horizonte, o projeto pretendeu instigar as/os estudantes a identificarem alguns "lugares de memória" no entorno da escola para transformá-los em espaços educativos e de referência histórico-cultural para a comunidade, a partir de suas pesquisas e da divulgação de seus resultados em um website acessado por meio de $Q R$ codes fixados nos locais. Concluímos que, ao se assumirem como protagonistas da construção do conhecimento histórico, professoras/es da

\section{ABSTRACT}

This paper discusses historical school knowledge through a real class room experience. That practice allowed students to exercise abilities such as research, interpretation and a qualified representation of the past. Developed at a public school in Belo Horizonte, among the final years of elementary school students, the project was intended to encourage students to identify some "memory places" around their school. The project also was intended to transform them into an educational place and a historical-cultural reference for the community. For this purpose, the results of the students' research were gathered on a website, which could be accessed through a QR code board fixed in these places. Our conclusion was that by assuming themselves as protagonists of historical knowledge, elementary school

\footnotetext{
*Universidade Federal de Minas Gerais (UFMG), Belo Horizonte, MG, Brasil. alessandrassantos@ hotmail.com

** Universidade Federal de Minas Gerais (UFMG), Belo Horizonte, MG, Brasil. renatohistoria1@ gmail.com
} 
educação básica e estudantes não se restringem a ensinar/aprender sobre o passado, mas se apropriam de uma linguagem específica capaz de desnaturalizar conceitos e ressignificar a diversidade de discursos sobre a História. Palavras-chave: ensino de História; História escolar; História local. teachers and elementary school students are not restricted to teaching or learning about the past, but can appropriate a specific language. This new ability is able to denaturalizing concepts and reframing historical narratives.

Key-Words: History teaching, historical school knowledge, local History.

Neste artigo, partimos da compreensão de que a escola é um lugar de relações dialógicas entre sujeitos históricos diversos envolvidos com a construção do conhecimento. A História aí ensinada e aprendida não se confunde com o conhecimento histórico acadêmico e sua complexa abordagem do passado, embora com ele estabeleça um diálogo. Tampouco se equipara à história de circulação massiva que produz uma interpretação simplificada e descompromissada com a mobilização da crítica de seus leitores/espectadores, embora também com ela dialogue. A história escolar possibilita o desenvolvimento de um exercício crítico que permite perceber o conhecimento histórico como uma construção cultural que possui a sua própria historicidade, bem como contribuir para desenvolver o sentimento de pertencimento social (BORNE, 1998; CERRI, 2011; ROCHA, MAGALHÃES e GONTIJO, 2009). Nesse sentido, de acordo com Rocha, Magalhães e Gontijo (2009, p. 16), "pode-se dizer que o objetivo da história escolar é ensinar/aprender a pensar historicamente, rompendo com as naturalizações e abrindo o horizonte de expectativas".

Mas para que seu objetivo seja alcançado, o conhecimento histórico escolar precisa superar a "colonização do presente pelo passado", como destacou Guimarães (2015), e abrir-se para práticas e metodologias que favoreçam interpretações mais pluralistas e menos monolíticas do passado e que permitam explorar as dissonâncias e contradições da história. Uma das preocupações do ensino de História das últimas décadas tem sido estabelecer relações e diálogos com as referências históricas que os estudantes trazem consigo antes mesmo da escolarização ou que constroem fora da escola por meio de seus jogos e filmes preferidos, bem como do uso de redes sociais. Frequentemente, entretanto, entre os saberes prévios da cultura histórica na qual os estudantes estão inseridos e o conhecimento histórico escolar são estabelecidas relações confli- 
tuosas de delicada superação. Alguns professores tendem a descartar esses saberes por considerá-los expressões de ideologias ultrapassadas ou fomentadores de atitudes e comportamentos discriminatórios ou, ainda, resultado de ensinamentos considerados equivocados (MONTEIRO, 2009). Cabe-nos, entretanto, como professores de História, viabilizar um processo dialógico de conscientização histórica por meio de reinvenções da aula de História na educação básica que permitam debater, negociar e complexificar os conhecimentos que os estudantes trazem com eles.

Se, por um lado, o processo educacional, como afirmou Guimarães (2015, p. 92), "tende sempre a extrapolar os muros da escola e ir ao encontro da comunidade e do lugar em que a escola se localiza - seja na trama urbana ou rural", por outro é interessante que o professor de História crie condições para que este diálogo aconteça dentro da sua disciplina. As aproximações da escola com a comunidade na qual ela se insere precisariam ir além dos eventos festivos ou comemorativos para fazer parte das ações dos professores no dia a dia da sala de aula. Para que os estudantes identifiquem e compreendam os processos históricos em sua profundidade, precisam encontrar significados para eles na sua própria realidade. Mas nem sempre os "conteúdos históricos" contidos em narrativas pré-definidas pela historiografia tradicional possuem relação direta, ou mesmo indireta, com a realidade dos estudantes.

Além disso, se por um lado há um consenso de que as práticas educativas precisam ser organizadas na relação com a vida cotidiana dos estudantes, por outro falta ainda, como destacaram Miranda e Siman (2013), radicalizar a compreensão de que as práticas de memória aí envolvidas organizam-se como componentes culturais e cognitivos centrais daquilo que se constituirá como base para o entendimento e a mobilização dos conteúdos curriculares da História enquanto disciplina escolar. Nesse sentido, do ponto de vista didático, as práticas educativas podem ultrapassar a produção de sínteses explicativas próximas ao estudante ou a elaboração de respostas a fenômenos e problemas, mas “ensejar o movimento intelectual que nos permita caminhar com o jovem e a criança no sentido de formular perguntas" (MIRANDA e SIMAN, 2013, p. 21).

Como exemplo, tomamos o caso da história da cidade de Belo Horizonte. Ainda que as histórias locais já estejam estabelecidas como um conhecimento que deve ser ensinado na escola, nem sempre os estudantes dos grandes centros urbanos se reconhecem nas memórias e nos monumentos selecionados como 
marcos dessa história local. Em nossa experiência como professores da educação básica, constatamos que os textos e atividades relativas à história de Belo Horizonte quase sempre abordavam a mesma dinâmica: interpretações monolíticas sobre o processo de transformação do arraial do Curral del Rei em uma cidade planejada para ser a nova capital de Minas Gerais, diferenciando pouco dos moldes de uma historiografia nacional. ${ }^{1}$ Quase nada dessa narrativa se diferenciava daquilo que tínhamos aprendido em nosso próprio processo de escolarização: uma história de fatos, acontecimentos, datas, atores e monumentos que pouco sentido fazia para a nossa necessidade de identificação e reconhecimento, uma vez que condizente com uma única escala temporal. Uma história na qual quem nasceu, cresceu e hoje trabalha nas periferias da cidade não se reconhecia e até hoje não se reconhece. A "história local", assim compreendida, terminava por não cumprir o seu papel de desnaturalizar a narrativa histórica, de ampliar as possibilidades de explorar um conjunto mais diversificado de fontes históricas em sala de aula, nem de engajar os estudantes em narrativas mais próximas da sua realidade.

Foi diante destas questões que desenvolvemos uma proposta de reinvenção das aulas de História nos anos finais do ensino fundamental da rede pública municipal de Belo Horizonte por meio do projeto "Caminhos da memória: um roteiro histórico com o uso do $Q R$ code nos lugares de memória no entorno da Escola Municipal Hélio Pellegrino (bairros Guarani-Aarão Reis, Belo Horizonte)". Este projeto foi elaborado como plano de ação pedagógica do curso de Pós-Graduação Latu Sensu Residência Docente para a Formação de Educadores da Educação Básica, oferecido pela Universidade Federal de Minas Gerais. O objetivo principal do projeto foi resgatar e criar, por meio da construção de um roteiro histórico no entorno da Escola Municipal Hélio Pellegrino, em Belo Horizonte, memórias e histórias que fossem significativas para os estudantes e a comunidade do bairro. ${ }^{2}$ Com as ações realizadas, os estudantes identificaram alguns "lugares de memória" e os transformaram em espaços educativos e de referência histórico-cultural a partir de suas pesquisas e da divulgação de seus resultados em um website acessado por meio de $Q R$ codes fixados nestes locais. Visamos com essa proposta não apenas promover a valorização e conservação destes lugares, mas sobretudo ressignificar a memória e a história local através de práticas de ensino que permitissem a problematização e a desnaturalização destes conceitos pelos estudantes. 


\section{RESSIGNIFICANDO OS CONCEITOS DE MEMÓRIA E REFERÊNCIA CULTURAL}

Ao elaborar o verbete "conhecimento histórico escolar" no Dicionário de ensino de História, Silva (2019) lembrou que ele se constrói por meio de relações de aproximações e distanciamentos com a História acadêmica, ou seja, "apesar de sua natureza complexa e específica, o conhecimento histórico escolar não abdica de aproximações, diálogos e tensões com a historiografia, com a teoria da história etc." (SILVA, 2019, p. 52). Nesse sentido, quando professores e estudantes se assumem como protagonistas na construção do conhecimento histórico, não se contentam em ensinar/aprender sobre o passado, mas buscam produzir instrumentos que permitam analisar, interpretar e construir sua própria representação do passado no presente. Assim a possibilidade da história escolar realizar mais eficientemente seu objetivo de, como bem sintetizado por Bittencourt (2004), "formar um cidadão comum com ferramentas intelectuais variadas para situar-se na sociedade e compreender o mundo físico e social em que vive" (BITTENCOURT, 2004, p. 47), torna-se maior.

Nem sempre, entretanto, existe a compreensão de toda a comunidade escolar para esta característica do ensino de História. Ainda perdura, em muitos espaços, a ideia de que as aulas de História se reduzem à "transmissão", pela mediação didatizada do professor, de um conhecimento que é produzido fora dela. Esta percepção, juntamente com a ideia de que a aula é o espaço para a aprendizagem de conteúdos sistêmicos e ordenados e com a pressão para "vencer o conteúdo" dos livros didáticos, acabam por impor limites às vezes intransponíveis para a introdução de novas práticas de ensino e aprendizagem. Essas dificuldades foram superadas na realização do projeto "Caminhos da memória: um roteiro histórico com o uso do $Q R$ code nos lugares de memória no entorno da Escola Municipal Hélio Pellegrino (bairros Guarani-Aarão Reis, Belo Horizonte)" com a colaboração de outros professores da escola e com um novo arranjo do espaço-tempo da aula de História convencionada.

Um grupo de trabalho com 28 estudantes do $6^{\circ}$ ao $9^{\circ}$ ano do ensino fundamental da Escola Municipal Hélio Pellegrino foi formado para o desenvolvimento deste projeto, de acordo com o seu interesse e disponibilidade para participar das ações propostas. Os estudantes foram organizados a partir de um levantamento daqueles que moravam ou não no bairro, para que formas- 
sem duplas de trabalho mistas com o objetivo de enriquecer as discussões por meio das percepções diferentes de quem vivia seu cotidiano dentro e fora daquele local que seria objeto de nossa investigação. As aulas aconteceram semanalmente ao longo do segundo semestre de 2019 e conversas sobre o andamento do projeto foram realizadas diariamente por meio da criação de um grupo em um aplicativo de celular de mensagens instantâneas para este fim exclusivo. Com o objetivo de promover o entrosamento de estudantes com idades e anos escolares diferentes e, ao mesmo tempo, propor uma reflexão sobre os espaços formais que guardam a memória e a história da cidade, realizamos uma visita orientada ao Museu da Escola Professora Ana Maria Casasanta Peixoto, antigo Centro de Memória da Educação de Belo Horizonte, que é parte do Circuito de Museus da Prefeitura Municipal de Belo Horizonte.

A partir daí, por meio da realização de entrevistas sobre a relação de cada um com o bairro, além de leituras e rodas de conversa, introduzimos a discussão sobre os conceitos de memória e de referência cultural. Os textos utilizados foram tanto literários quanto trechos de obras acadêmicas. ${ }^{3}$ Pretendemos, com eles, questionar as ideias de neutralidade e espontaneidade da memória e, com isso, promover o entendimento das questões que envolvem o processo de construção da memória e das referências culturais no interior dos grupos identitários. Os estudantes compreenderam que a noção de referência cultural não se restringe ao aspecto material da cultura, mas envolve a diversidade de sentidos e valores que diferentes sujeitos os atribuem a estes bens. Não se trata, portanto, de considerar apenas o valor histórico e artístico destes bens, mas a dimensão simbólica deles para os habitantes do lugar, as dinâmicas de práticas, usos e costumes envolvidos. Daí que uma referência cultural só assim se constitui quando é considerada e valorizada enquanto marcas distintivas por sujeitos definidos (INVENTÁRIO, 2000).

Esta percepção se tornou ainda mais clara para os estudantes com a realização de uma segunda visita orientada aos lugares de memória consolidados da cidade de Belo Horizonte, o Museu Histórico Abílio Barreto (MHAB). Antes de conhecer a exposição permanente deste que é um dos lugares de referência para o conhecimento da história da cidade, os estudantes foram orientados a produzir um esboço sobre como enxergavam o museu e o que esperavam encontrar no MHAB que pudesse estar ligado à história dos bairros Guarani e Aarão Reis. Com suas pranchetas para anotações e celulares na mão, 
tiveram ainda a tarefa de fazer pelo menos duas fotografias da exposição para fomentar a discussão do grupo de mensagens instantâneas. Nesta oportunidade, os estudantes também visitaram a exposição temporária "NDÊ! Trajetórias afro-brasileiras em Belo Horizonte", na qual foram apresentados a personagens invisibilizados com a construção da nova capital de Minas Gerais. Dessa forma, puderam relacionar a história e a memória guardada pelo $\mathrm{MHAB}$ com as trajetórias paralelas de conquistas e resistências de moradores-personagens pouco conhecidos, como os do bairro Guarani.

Compartilhamos com Guimarães a pressuposição de que

é necessário reconhecer que, na cidade, temos espaço/tempo plural, que teve por contexto a trama urdida por tensões e conflitos, latentes ou manifestos, passíveis de serem rastreados pela emergência de novas sensibilidades e sociabilidades, que passaram a compor a experiência do viver na urbis. (GUIMARÃES, 2015, p. 99-100)

Nesse sentido, algumas observações dos estudantes podem ser reveladoras do aproveitamento que tiveram. Na roda de conversa com os mediadores do $\mathrm{MHAB}$, eles foram apresentados à história de uma antiga moradora-personagem do Arraial Del Rei, Maria Papuda. A luta dela pela conquista de melhores condições de moradia na nova capital foi comparada à luta dos moradores-personagens do bairro Guarani por luz, água encanada e meios de transporte públicos: "é engraçado porque a gente nem sabe muito sobre eles, mas sabemos que foram importantes", disse uma das estudantes. O momento marcou um conceito importante para a compreensão do processo de lembrança e esquecimennto realizado na construção da memória da cidade: invisibilização. Muitos que construíram a capital eram negros e pobres assim como aqueles que lutaram no bairro Guarani para terem melhores condições de vida. Essas pessoas acabaram sendo esquecidas pelos interesses daqueles que tiveram o poder de selecionar o que seria lembrado na história da cidade. A observação feita por dois estudantes dá a dimensão do esquecimento: as principais vias do bairro ganharam o nome de políticos importantes para a cidade, como Waldomiro Lobo e Cristiano Machado. Mas as pessoas do bairro ficaram em segundo plano ou, segundo eles disseram, "não são lembradas nem para nome de rua".

Com essas atividades, trabalhamos o tema da memória nas aulas de História na perspectiva indicada por Gil (2019) no sentido de compreendê-la 
como um campo aberto ao debate e à compreensão das sociedades em diferentes tempos. Para desnaturalizar as representações hierarquizadas e promover diálogos possíveis entre elas, realizamos a abordagem da tradição oral como algo tão importante quanto a tradição escrita, valorizando a fala e a escuta. Buscamos compreender que "a memória social não se reduz ao que está nos livros" e reconhecer "os mestres e griôs diante das novas gerações e dos sistemas formais de ensino", superando assim a colonialidade do poder e a colonização do presente pelo passado (GIL, 2019, p. 160; GUIMARÃES, 2015, p. 95), como mostram as ações propostas em seguida.

\section{DA MEMÓRIA À HISTÓRIA ESCOLAR: A CONSTRUÇÃO DOS “LUGARES DE MEMÓRIA” DO BAIRRO}

De acordo com Nora (1993, p. 13), “os lugares de memória nascem e vivem do sentimento de que não há memória espontânea”. Os espaços tradicionais que remetem à lembrança do passado (arquivos, museus, celebrações, elogios fúnebres etc.) foram construídos por grupos imbuídos de legitimidade e poder para fazê-los. Mas esses focos privilegiados da memória deixaram de ser espaços de reconhecimento de uma identidade coletiva válida para todos os grupos quando a fragmentação do sujeito moderno promoveu o deslocamento e a instabilidade do reconhecimento cultural e social que os indivíduos fazem de si mesmos. O resultado desse processo foi a emergência de múltiplas identidades que criaram suas "memórias refugiadas", isto é, alheias aos espaços canonizados como "lugares de memória". As minorias compreenderam que, sem ferramentas para preservar as suas próprias memórias, ficariam alijadas da História. Este também foi um dos aprendizados dos estudantes engajados no projeto.

A ausência de monumentos (estátuas, bustos, efígies, esculturas etc.) no espaço urbano das periferias de Belo Horizonte é reveladora do deslocamento da memória da história da capital mineira como produtora de identidade social nestes lugares. Esta ausência está documentada no Inventário dos Monumentos de Belo Horizonte, produzido pela Empresa Municipal de Turismo de Belo Horizonte (Belotur). A regional Norte da cidade não possui nenhum dos 198 monumentos catalogados (CRUVINEL, 2012). Por outro lado, aí se localiza o primeiro terreiro de candomblé de Belo Horizonte, o Ilê Wopo Olojukan, tom- 
bado como Patrimônio Cultural do Povo Negro, atendendo às reivindicações do movimento negro pelo direito à memória.

Cabe aqui ressaltar nossa percepção de que, entre o conhecimento histórico escolar e a história cotidiana do bairro, não estabelecemos uma lógica dicotômica. Como bem lembrou Caimi (2013), um dos principais desafios que se colocam para a escola e para a história escolar nestes tempos de democratização das tecnologias de informação e comunicação é como se aproximar da vida presente. Para isso, vale encarar as mudanças na forma como os saberes circulam na sociedade, não mais restritos aos livros e à escola, nem mesmo limitado ao tempo escolar. De acordo com Caimi,

enfrentar tais desafios parece condição para vitalizar o papel da história escolar na gestão da memória, na construção/reconstrução das identidades e na legitimação/desconstrução dos saberes. Ao voltar os olhos para o passado, precisamos fazê-lo na perspectiva dialógica, buscando a multiplicidade de falas, gestos, rituais e sentidos, potencializando a construção de identidades múltiplas e plurais. (CAIMI, 2013, p. 31)

Para que essa memória se transforme em história, como afirmou Nora (1993), ela precisa se apoiar no registro, no material, em algo visível: "ela tem necessidade de suportes exteriores e de referências tangíveis de uma existência que só vive através delas" (NORA, 1993, p. 14). Assim, os estudantes foram instigados a identificarem determinados elementos do bairro como particularmente significativos para quem nele mora e convive, com o cuidado de fazer desta ressemantização uma representação coletiva em que cada morador de algum modo se identifique. Consideramos que "o ato de apreender 'referências culturais' pressupõe não apenas a captação de determinadas representações simbólicas como também a elaboração de relações entre elas, e a construção de sistemas que 'falem' daquele contexto cultural no sentido de representá-lo" (INVENTÁRIO, 2000, p. 14).

Por isso, propomos que os estudantes realizassem entrevistas com alguns personagens do bairro. Eles deveriam escolher um morador que conhecesse bem o bairro e que pudesse auxiliá-los nas questões propostas pelo projeto, levando em consideração alguns critérios como idade e tempo de vivência no bairro. Sugerimos que fossem feitos registros dessas entrevistas, preferencialmente no celular, para captação de áudio e vídeo. Nesse trabalho com a memó- 
ria e a história oral, buscamos compreender o passado em suas diferentes vozes, daí que abordamos estes testemunhos não como fonte acessória, mas, como propôs Gil (2019), como o núcleo de um estudo com os estudantes. Assim encaramos o desafio de debater na escola as presenças e as ausências dos grupos sociais da comunidade do bairro, considerando a memória como um trabalho do presente, pois

a memória coletiva não é uma entidade que existe acima dos indivíduos, não se trata de dados e, por isso, é importante centrar a atenção nos processos de sua construção, evidenciando os diferentes sujeitos sociais e as disputas de sentidos, de modo que a história cumpra sua tarefa de fazer o debate explicitando as escolhas e as negociações da memória. (GIL, 2019, p. 160-161)

As duplas de trabalho produziram um diversificado material com testemunhos e depoimentos valiosos para a pesquisa. No conjunto de perguntas realizadas, previamente roteirizadas, os moradores tiveram oportunidade de falar sobre como e por que escolheram aquele bairro para viver, como era sua casa e sua escola na infância, como eram as ruas e avenidas principais, como se relacionavam com a paisagem natural, qual local ou prática do cotidiano existia no passado e que sentem falta no presente, o que eles sabiam sobre os locais mais antigos do bairro e quais locais de referência histórica e cultural eles destacavam no bairro. Como bem observou Oliveira (2013) quando analisou as relações entre memória e objeto no estudo das cidades, os estudantes estabelecem uma forte ligação entre o passado e o presente pela mediação dos relatos, das memórias que vêm do outro, da marca humana nos objetos. Foi também o que observamos na realização dessa atividade.

Com o resultado de suas entrevistas em mãos, os estudantes apresentaram para os colegas os "moradores-personagens" do bairro. Reforçamos com essa expressão a ideia de que são estes moradores os personagens principais de suas histórias de vida e da história coletiva. O que percebemos da análise do conjunto do material produzido pelos estudantes foi que os moradores entrevistados enfatizaram na história do bairro a construção de um território marcado por lutas e resistências, com conquistas diversas. ${ }^{4}$ Além da coleta de informações, a atividade estimulou a percepção do protagonismo de cada um na cons- 
trução da própria história e da história coletiva, colocando-os na condição de agentes que constroem, interpretam e ressignificam o próprio passado.

O passo seguinte foi propor uma aula na qual os estudantes pudessem compartilhar suas pesquisas sobre os lugares de referência histórica e cultural levantados por cada dupla em suas entrevistas e conversas com os moradores mais antigos do bairro. Nas apresentações, eles justificaram os motivos que levaram os entrevistados a considerar cada local como lugar de memória e fizeram um mapeamento dos mesmos. Assim, as memórias dos moradores por eles entrevistados subsidiaram a seleção de alguns locais transformados em "lugares de memória" e que fariam parte do roteiro a ser elaborado: a Escola Municipal Hélio Pellegrino, o Parque Municipal Nossa Senhora da Piedade, a sede da Sociedade Comunitária do Bairro Guarani, a "farmácia do Edmilson" (atual Drogalina), o terreiro de candomblé Ilê Wopo Olojukan e a Pizzaria Guarani.

$\mathrm{Na}$ aula seguinte, fizemos uma prévia do percurso caminhando com a turma pelos lugares de memória selecionados e fomos definindo, com a ajuda de um aplicativo de localização do celular, a melhor ordem para a visitação daqueles espaços, bem como as possibilidades e dificuldades para a organização do roteiro, considerando as ruas e caminhos percorridos. Nessa oportunidade, aproveitamos para estabelecer os primeiros contatos com os responsáveis pelos lugares para informar sobre a realização do projeto e viabilizar a pesquisa in loco dos estudantes. As pesquisas foram realizadas em fontes da internet e, principalmente, por meio dos depoimentos orais de pessoas ligadas a cada um dos lugares.

Paralelamente à pesquisa, um grupo de estudantes também se encarregou de criar um logotipo para o projeto, os $Q R$ codes e um website no qual foram guardadas as informações da pesquisa realizada. Essas informações podem ser acessadas diretamente dos lugares por meio de $Q R$ codes inscritos em placas de acrílico que foram instaladas em cada um dos espaços de memória selecionados por eles.

O BAIRRO COMO ESPAÇO EXPOSITIVO: O USO

DE QR CODES COMO “TECNOLOGIA DA MEMÓRIA”

Para Pierre Levy (2008), vivemos um mundo novo no qual a memória da humanidade não está mais registrada na forma impressa, mas digital, e dispo- 
nibilizada para acesso online. O ciberespaço, que é onde essa digitalização da vida se realiza, compõe-se por um infinito banco de memórias, sejam elas de curta ou longa duração. Essas memórias não se encontram mais fragmentadas, elas podem ser reunidas em conjunto "como se nós tivéssemos uma única biblioteca reunindo todas as bibliotecas, todos os centros de documentação, todos os jornais etc. - tudo reunido exatamente no mesmo espaço e automaticamente manipulável por meio de programas" (LEVY, 2008, s. p.). Pensando nisso e inspirados pela adaptação que os espaços de exposição museográfica fizeram das novas práticas sociais e culturais no uso das tecnologias de informação, lançamos mão do uso de $Q R$ codes como forma de acesso público ao resultado das pesquisas realizadas pelos estudantes.

Os QR codes (Quick Response Codes) são códigos bidimensionais que possuem uma grande capacidade de armazenamento e que, ao serem focados pela câmera de um celular, funcionam como um link que permite o acesso a conteúdos multimídia hospedados na web. Os $Q R$ codes são largamente utilizados em vários centros expositivos como uma tecnologia auxiliar na mediação cultural de objetos museográficos e obras de arte para ampliar o acesso às informações sobre os mesmos (TORRES, 2015). Por tratar-se de um recurso relativamente simples e econômico em relação a outras tecnologias, o $Q R$ code está democratizado em diferentes instituições e espaços de memória e popularizado em diversas práticas do cotidiano e, por isso, adequou-se perfeitamente aos propósitos do projeto de ação desenvolvido. Além disso, para Lévy (1993), este tipo de mídia interativa adequa-se particularmente aos usos educativos, uma vez que

é bem conhecido o papel fundamental do envolvimento pessoal do aluno no processo de aprendizagem. Quanto mais ativamente uma pessoa participar da aquisição de um conhecimento, mais ela irá integrar e reter aquilo que aprender. Ora, a multimídia interativa, graças a sua dimensão reticular ou não linear, favorece uma atitude exploratória, ou mesmo lúdica, face ao material a ser assimilado. É, portanto, um instrumento bem adaptado a uma pedagogia ativa. (LÉVY, 1993, p. 40)

O conhecimento prévio dos estudantes sobre a geração dos $Q R$ codes de forma gratuita e sobre a criação de websites foi fundamental nessa etapa do projeto. As equipes, sob a orientação do professor, trabalharam em sintonia para desenvolver o layout e a criação dos menus, articulando a redação dos 
textos sobre cada lugar, a escolha das imagens e a construção de cada página. Foram criadas placas no tamanho A4 para fixação nos lugares de memória com o registro do QR code que direciona para as informações de cada lugar do bairro no website. ${ }^{5}$ Além disso, foi elaborado um fôlder impresso com informações do projeto e com um mapa do roteiro elaborado pelos estudantes para ser divulgado na comunidade escolar e dos bairros envolvidos. O financiamento dessa produção (hospedagem do website, impressão das placas e dos fôlderes) foi feito com recursos da Escola Municipal Hélio Pellegrino e do Centro Pedagógico da UFMG.

Resta-nos indagar quais memórias a tecnologia dos $Q R$ codes guardam no ciberespaço a partir do resultado das pesquisas dos estudantes sobre alguns lugares do bairro. É interessante observar que essa "tecnologia da memória" funciona como uma mediadora cultural do conhecimento histórico escolar na comunidade e vale a pena conhecer seu potencial para impactar as memórias coletivas construídas com a contribuição desse conhecimento. Isso se torna significativo na medida em que o projeto transformou a relação da escola com a comunidade numa via de mão dupla: por um lado trouxe os documentos e testemunhos orais para a sala de aula por meio de pesquisas e entrevistas e, por outro, levou o conhecimento produzido na escola para a comunidade através da criação de um roteiro histórico e da organização da memória local. Dessa forma, os estudantes contribuíram, com seu conhecimento, para a dinâmica da memória da comunidade na qual estão inseridos.

Na pesquisa sobre a Escola Municipal Helio Pellegrino, ponto de partida do roteiro histórico local proposto, os estudantes enfatizaram que sua fundação em 1995 foi fruto da ação comunitária para realizar uma demanda antiga dos moradores do bairro. Ao mesmo tempo em que ressaltaram as ações coletivas realizadas desde a década de 1980, como manifestações públicas em passeatas, abaixo-assinados, missas, cultos e na imprensa, também destacaram o nome de uma liderança feminina na condução das mobilizações, a presidente da Associação Comunitária do Bairro Guarani, Maria Teresa Souza Costa. Esta associação, atualmente chamada de Sociedade Comunitária do Bairro Guarani (SCOBAG), foi escolhida como o segundo lugar de memória do roteiro justamente por sua importância para a história de lutas e conquistas do bairro, como a escola, o posto de saúde e o antigo posto policial. Além de Maria Teresa Souza Costa, aparece no texto o nome de outra liderança feminina, Geralda 
Maria de Oliveira, mostrando como os estudantes fizeram questão de ressaltar a efetiva participação das mulheres na história do bairro.

$\mathrm{O}$ roteiro continua com o destaque para dois espaços privados que são referência tanto do ponto de vista dos moradores do bairro, quanto de quem vem de outras regiões da cidade: a Pizzaria Guarani e a Farmácia Drogalina. Em relação à pizzaria, os estudantes enfatizaram sua história como exemplo de empreendedorismo no final da década de 1970 levado a cabo por mais uma mulher, Maria Jorge da Silva, fundadora do estabelecimento, que foi entrevistada por eles. Sobre a farmácia, inaugurada em 1981 por Edmilson Carneiro - daí ser conhecida popularmente como Farmácia do Edmilson -, os estudantes ressaltaram sua importância para a vivência comunitária, uma vez que por ali passavam todos os moradores do bairro.

Por fim, dois lugares localizados no bairro Aarão Reis completam o roteiro histórico proposto pelos estudantes: o Parque Municipal Nossa Senhora da Piedade, inaugurado em 2008, e o terreiro de candomblé Ilê Wopo Olojukan, construído em 1964 e reconhecido oficialmente como a mais antiga comunidade-terreiro e patrimônio cultural da cidade de Belo Horizonte. Como lugar de memória de fundação mais recente, o Parque Municipal Nossa Senhora da Piedade adquiriu importância para a comunidade, do ponto de vista dos estudantes, por ser resultado de uma política de preservação ambiental com foco nas necessidades da população local. Além de recuperar e despoluir o córrego presente ali, que era apontado como principal causa de doenças entre os moradores, a área de $58 \mathrm{mil} \mathrm{m}^{2}$ está ocupada por uma vegetação diversificada e por equipamentos que favorecem a convivência e a prática esportiva e de lazer. Por outro lado, uma das referências mais antigas da comunidade, o terreiro de candomblé Ilê Wopo Olojukan, marco das reivindicações do movimento negro pelo direito à memória, não foi escolhido pelos estudantes sem que eles mesmos manifestassem a necessidade de discutir como a pesquisa sobre o lugar poderia ser realizada sem que despertasse resistência e preconceitos dentro de suas próprias famílias, identificadas com outras religiões. Nesse sentido, para eles também a inclusão do terreiro no roteiro histórico foi uma ação de reconhecimento e superação de preconceitos que perpassam as religiões afro-brasileiras. 


\section{CONSIDERAÇÕES FINAIS}

Ao tratar das finalidades do ensino de História, Borne (1998) sintetizou aquilo que para nós, professores de História da educação básica, é uma das tarefas fundamentais de nossa prática docente:

ensinar a história é, em primeiro lugar, levar os alunos a se apropriarem de uma linguagem específica. (...) Apropriar-se de uma linguagem não passa por uma simples memorização, e sim pela aprendizagem das operações intelectuais que permitem a construção de um discurso. Como historiador, mas no nível que lhe é próprio, o aluno deve descobrir, analisar, classificar. Em suma, operar um ordenamento no tempo. (...) Pouco a pouco, os alunos aprendem as operações que conduzem a "fazer história". A história não é dada a priori, ela se constrói. Manipular dados e, combinando-os, produzir sentido: a história é uma aprendizagem do exercício do pensamento lógico e crítico. (BORNE, 1998, p. 139)

O domínio desta linguagem específica que é a linguagem do conhecimento histórico, segundo o mesmo autor, abre a possibilidade da aprendizagem da liberdade - pelo conhecimento da diversidade das possibilidades de vida -, da tolerância - pelo afastamento do medo daquilo que é desconhecido -, e da solidariedade - pela construção de uma comunidade de memória livremente escolhida.

Acreditamos que o desenvolvimento do projeto "Caminhos da memória: um roteiro histórico com o uso do $Q R$ code nos lugares de memória no entorno da Escola Municipal Hélio Pellegrino (bairros Guarani-Aarão Reis, Belo Horizonte)" cumpriu a tarefa acima referida na medida em que viabilizou não apenas a familiarização com esta linguagem específica do conhecimento histórico, mas principalmente a sua apropriação pelos estudantes. A partir de um problema do seu presente - a ausência de referências históricas locais para a identificação da sua comunidade - eles pesquisaram informações, produziram fontes orais, analisaram esse material e estabeleceram conexões para criar uma narrativa (um ordenamento no tempo) sobre os lugares de memória do bairro.

Além disso, ao se transformarem em agentes da problematização histórica, os estudantes tiveram oportunidade de desnaturalizar os conceitos de história e de memória produzindo um conhecimento histórico escolar novo, crítico, apartado daquela sucessão de fatos sobre o passado, nem sempre sufi- 
cientes para responder às demandas do presente. Arriscamos afirmar que o projeto também contribuiu para estabelecer e/ou reforçar os laços de solidariedade entre os estudantes e a comunidade, cruzando os caminhos da memória da comunidade e do conhecimento histórico dos estudantes que enriqueceram as experiências de ambos.

\section{REFERÊNCIAS}

BITTENCOURT, Circe Maria Fernandes. Ensino de História: fundamentos e métodos. São Paulo: Cortez, 2004.

BORNE, D. Comunidade de memória e rigor crítico. In: BOUTIER, J.; JULIA, D. Passados recompostos: campos e canteiros da história. Rio de Janeiro: FGV, 1998, p. 183- 141.

CAIMI, F. E. Cultura, memória e identidade: o ensino de história e a construção de discursos identitários. In: SILVA, C. B.; ZAMBONI, E. (Orgs.). Ensino de História, memória e culturas. Curitiba, CRV, 2013, p. 17-33.

CERRI, L. F. Ensino de história e consciência histórica: implicações didáticas de uma discussão contemporânea. Rio de Janeiro: FGV, 2011.

CRUVINEL, E. H. P. Monumentos, Memória e Cidade: estudo de caso em Belo Horizonte. Dissertação de Mestrado. Escola de Arquitetura da UFMG, 2012.

GIL, C. Z. V. Memória. In: FERREIRA, M. M.; OLIVEIRA, M. M. D. (Coord.). Dicionário de ensino de história. Rio de Janeiro: FGV, 2019, p. 155-161.

GUIMARÃES, M. F. Patrimônio cultural e ensino de história: problematizando a colonização do presente pelo passado. In: ZAMBONI, E.; GALZERANI, M. C.; PACIEVITCH, C. (Orgs). Memória, sensibilidades e saberes. Campinas: Alínea, 2015, p. 90-102.

INVENTÁRIO nacional de referências culturais: manual de aplicação. Brasília: IPHAN, 2000.

LEVY, P. Memória e cibercultura. Entrevista concedida a Lynnda Proulx e Maria Antonieta Pereira. Disponível em: http://www.letras.ufmg.br/atelaeotexto/entrevista_ levy.html. Ottawa, junho de 2008. Acesso em 20/06/2020.

LEVY, P. As tecnologias da inteligência: o futuro do pensamento na era da informática. Rio de Janeiro: Editora 34, 1993.

MIRANDA, S. R.; SIMAN, L. M. C. A cidade como espaço limiar: sobre a experiência urbana e sua condição educativa, em caminhos de investigação. In: Cidade, memória e educação. Juiz de Fora: UFJF, 2013, p. 13-37. 
MONTEIRO, A. M. Ensino de História: entre história e memória. Anais do I Seminário de Pesquisa e Práticas Educativas: os desafios da pesquisa no ensino de História. Rio de Janeiro: UFRJ, 2009.

NORA, Pierre. Entre memória e história: a problemática dos lugares. Projeto História. São Paulo, n. 10, dez. 1993, p. 7-28.

OLIVEIRA, S. R. F. Relações entre memória e objeto no estudo das cidades. In: SILVA, C. B.; ZAMBONI, E. (Orgs.). Ensino de História, memória e culturas. Curitiba, CRV, 2013, p. 135-150.

ROCHA, H.; MAGALHÃES, M.; GONTIJO, R. A aula como texto: historiografia e ensino de história. In: A escrita da história escolar: memória e historiografia. Rio de Janeiro: FGV, 2009. SILVA, Cristiane Bereta da. Conhecimento histórico escolar. In: FERREIRA, Marieta de Moraes; OLIVEIRA, Margarida M. Dias (Coord.). Dicionário de Ensino de História. Rio de Janeiro: FGV, 2019.

TORRES, David Ruiz. Ciber-memória do processo criativo do artista: uso de QR codes em espaços expositivos. In: DE JESUS, S. (Org.). Anais do VIII Seminário Nacional de Pesquisa em Arte e Cultura Visual: arquivos, memórias, afetos. Goiânia: UFG/Núcleo Editorial FAV, 2015.

\section{NOTAS}

${ }^{1}$ Exceção pode ser dada às coleções paradidáticas Histórias de Bairros de Belo Horizonte, produzida pelo Arquivo Público da Cidade de Belo Horizonte (APCBH), em 2011, e Onde mora a minha história?, do Museu Histórico Abílio Barreto (MHAB), 2007.

${ }^{2}$ Este projeto de ação recebeu o reconhecimento da Aliança Brasileira pela Educação por meio de uma premiação para práticas educativas que visassem apoiar o alto desempenho dos alunos em leitura, escrita, cálculos, resolução de problemas e atividades colaborativas - o Prêmio Charles Lofti Edição 2019. A Escola Municipal Hélio Pellegrino, onde o projeto foi realizado, e o professor Renato Sena Ramos, responsável pela execução da proposta, foram contemplados com o $2^{\circ}$ Prêmio - Faixa Prata de Melhor Prática pela realização desse projeto.

${ }^{3}$ Destacamos o livros de Mem Fox, Guilherme Augusto Araújo Fernandes, publicado pela editora Brinque-Book em 1995, trechos do livro de Jacques Le Goff, História e memória, publicado pela editora da Unicamp em 1994, e do artigo de Michael Pollak, Memória e identidade social, publicado pela revista Estudos históricos em 1992.

${ }^{4}$ Os bairros Guarani e Aarão Reis se localizam na região norte de Belo Horizonte. Originalmente situados numa área de fazendas que abasteciam Belo Horizonte durante a sua construção, sua ocupação teve início com a abertura de uma estrada para a cidade de Santa Luzia (atual Rua Benedito Xavier). O loteamento do bairro Guarani foi oficializado em 
1948 e do bairro Aarão Reis em 1956. Até 1980, a situação desses bairros era bastante precária, sem meios de transporte coletivo, água encanada, pavimentação de ruas, escolas etc. Foi quando os moradores se organizaram para solicitar os serviços de estrutura básica junto à Prefeitura. Para outras informações sobre esses bairros e a região ver as publicações: Histórias de bairros de Belo Horizonte: regional Norte. Belo Horizonte: APCBH, 2011; Onde mora a minha história? Bairro Guarani. Belo Horizonte, MHAB, 2007.

${ }^{5} \mathrm{O}$ website criado pelos estudantes pode ser acessado através do endereço https://www. caminhosdamemoriaemhp.com.br/.

Artigo submetido em 27 de julho de 2020. Aprovado em 17 de outubro de 2020. 